\title{
Transformações sócioambientais: uma reflexão sobre a construção do urbano
}

\section{Social-environmental transformations: a reflection on the construction of the urban}

DOI: $10.46814 /$ lajdv3n4-010

Recebimento dos originais: 01/05/2021

Aceitação para publicação: 31/06/2021

\author{
Josefina Rocha Oliveira \\ Esp. \\ UNIBAHIA - Pós graduação em Educação Ambiental \\ Professora da Educação Básica no Colégio Estadual Padre Luiz Soares Palmeira \\ Rua Local E, Urbis V, 90 - Bairro Zabelê, Vitória da Conquista/BA. \\ E-mail: josefinarochaoliveira@gmail.com \\ Inalice Donato Primo Menezes \\ Esp. \\ UNIBAHIA - Pós graduação em Educação Ambiental \\ Coordenadora Pedagógica da Escola Municipal Professora Marlene Flores \\ Rua Margarida Oliveira Cunha, S/N - Bairro Lagoa das Flores, Vitória da Conquista/ BA. \\ E-mail: nalidonato@gmail.com
}

\begin{abstract}
RESUMO
Diante das inúmeras transformações socioespaciais ocorridas através da apropriação do meio natural, verifica-se a complexidade das relações que se solidificam na produção do espaço urbano. Partindo dessa premissa, buscou-se através deste, discutir a problemática urbana responsável pela dinâmica socioespacial que emerge das desigualdades pertinentes às classes, e que acentuam as questões ambientais. Assim, a cidade apresenta-se por meio de contradições sociais, das ocupações humanas desordenadas, desmatamentos e especulações imobiliárias. A apropriação do solo urbano expressa na paisagem as relações materiais vividas em cada momento histórico, sobrepondo de forma diferenciada e fragmentada a depender do seu conteúdo social. Contudo, desconsiderar as características naturais, por meio do crescimento desordenado, com a ocupação das encostas, margens dos rios, além da impermeabilização dos solos demonstra o descaso com o meio ambiente. Neste contexto, na divisão social do espaço, os serviços de infraestrutura tem caráter valorativo, e quando em sua ausência, acarreta sérios problemas ambientais. Dentro desta lógica existem os produtores do espaço urbano, como o poder público, que ao dispor das suas atribuições de zoneamento, calçamentos, serviços de esgoto, iluminação, coleta de lixo etc., atua na construção da cidade seja atraindo, ou expulsando os moradores, a depender de onde e como os serviços são disponibilizados. Neste sentido, o planejamento urbano, constitui um diferencial relevante na construção de uma cidade sustentável. Deste modo, a proposta por um trabalho teórico de reflexão visa fomentar um tema que não se esgota, mas sim permite indagar sobre as transformações do meio a partir da articulação dos grupos sociais.
\end{abstract}

Palavras-chave: Paisagem, relações sociais, cidade, meio ambiente.

\section{ABSTRACT}

Considering the many changes occurring through socio ownership of the natural environment, there is the complexity of relationships that solidify in the production of urban space. On that premise, it 
was through this, to discuss urban issues for dynamic socio relevant inequalities that emerge from the classes, which emphasize environmental issues. Thus, the city has been based on the social contradictions of uncoordinated human activities, deforestation and real estate speculation. The ownership of urban land as expressed in the relationship landscape materials experienced in every historical moment, of overlapping and fragmented differently depending on the their social content. However, disregarding the natural characteristics, by the disorderly growth, with the occupation of slopes, banks of rivers, in addition to the sealing of the soil shows the disregard for the environment. In this context, the social division of space, the services infrastructure has character values, and when in his absence, causes serious environmental problems. Within this logic there are producers of urban space, like public power, that the disposal of its powers of zoning, paving services, drainage, lighting, garbage collection etc., Operates in the construction of the city is attracting or expelling the residents, depending on where and how services are provided. In this sense, the urban planning, is an important gap in building a sustainable city. Thus the proposal for a work of theoretical reflection to promote a theme that is not exhausted, but can ask about the change in media from the articulation of social groups.

Keywords: Landscape, social, city, environment.

\section{INTRODUÇÃO}

Numa abordagem geral sobre a apropriação espacial e os diferentes usos do solo, fazse necessário um resgate histórico no intuito de facilitar a compreensão dos acontecimentos humanos que permearam o processo de ocupação e construção do espaço urbano. As relações tecidas no âmbito social envolvem as interações dos indivíduos de diversas classes e grupos com a natureza, tendo em vista que as alterações deste espaço são motivadas pela evolução da humanidade em seus respectivos contextos. Ou seja, compreender as mudanças ocorridas na natureza implica em refletir sobre as transformações que aconteceram nos indivíduos que dela fazem uso.

Diante disso, o estudo a seguir aborda uma reflexão teórica sobre os problemas socioambientais na configuração do espaço urbano, considerando as necessidades humanas no decorrer dos anos, bem como as interferências da gestão pública no crescimento das cidades.

\section{APROPRIAÇÃO DO ESPAÇO}

Na história da civilização, o domínio da natureza pelo homem é um acontecimento que se intensifica cada vez mais. Desde o seu surgimento, a espécie humana foi desenvolvendo novas tecnologias e ampliando o seu poder de apropriação do espaço, principalmente através do aperfeiçoamento dos modos de produção. Por isso, ao se apossar de mais áreas para suprir suas necessidades o homem começa a desenvolver vínculos de produção e de sociabilidade, sendo que o dinamismo humano reside na alteração do espaço habitado. 
Inicialmente a dependência do homem em relação à natureza se resumia, principalmente, a oferta de alimentos. Posteriormente, a fixação em um determinado lugar o obrigou a desenvolver habilidades essenciais para sua sobrevivência, como: construção de casas, manejo do solo, uso do fogo etc. A partir de então, dá-se a produção dos espaços diferenciados através do tempo, decorrente da variação de região e cultura. Neste contexto, a cidade se apresenta com linguagem própria, particularidades de cada local que são expressas nas conversas, no modo de vestir e de agir dos seus habitantes, além da disposição dos elementos urbanos.

A materialização dos processos de interação entre a sociedade e a natureza é compreendida numa dimensão histórica, ou seja, as relações humanas que se concretizam no espaço representam as funções que cada lugar estabelecia em determinado contexto. Para Sánchez (apud SCHWENK \& CRUZ 2004), a sociedade adota múltiplas formas sistêmico-estruturais no espaço e no tempo. Assim, cada sociedade é organizada diferentemente, de acordo com as variáveis que a definem, com as diferentes estruturas sociais em conformidade com seus objetivos e articulações internas e com seus valores.

\section{O DESENVOLVIMENTO DAS CIDADES}

As sociedades agrícolas já apresentavam impactos na dinâmica dos ecossistemas e na distribuição das espécies, na medida em que desmatavam para utilização do solo. No inicio da industrialização continuou a intervenção através da exploração e exportação dos recursos naturais, em prol das condições de sobrevivência da população. Hoje, os padrões da sociedade vigente são os principais responsáveis pela crise ambiental.

Partindo deste pressuposto, o modo como nos inserimos no ambiente resulta em um conjunto de relações sociais que, por sua vez, promove uma interação específica com o meio natural. Todavia, esse relacionamento encontra-se em descompasso, onde o individualismo e a competitividade regem o modelo de sociedade existente. Sobre isso, Sorretino (2002) destaca que:

\footnotetext{
Descobrimos que nossos destinos estão irremediavelmente ligados e que a complexa matriz de tomada de decisão exige uma capacidade expansiva de inclusão, negociação, descentralização, enraizamento, autogestão e compreensão da interdependência entre tudo e todos, sobre qual não temos dado muitas provas de competência (SORRETINO, 2002, p.16)
}

A falta de percepção por parte da humanidade, que cria e recria seu espaço à custa da apropriação da natureza, impede de visualizar a complexa relação existente entre o homem e o meio ambiente. Percebe-se que o capital natural da terra vem sendo ameaçado a cada dia devido aos avanços de fronteira econômica, expansão agrícola, assentamentos humanos desordenados, 
desmatamentos e especulações imobiliárias que, por falta de projeto de prevenção, acabam remediando os danos depois de fragmentá-los.

Embora as modificações decorrentes da globalização indiquem para uma aparente homogeneização dos espaços, a partir da difusão de características comuns, as relações se intensificam pela manutenção das diferenças, já que essas são utilizadas para suprir possíveis ausências. Neste sentido, os hábitos e costumes são de essencial relevância para o estabelecimento das peculiaridades espaciais. Assim, percebe-se que a construção do meio urbano se dá pela concretização das relações sociais, articuladas através da mobilidade populacional na dinâmica territorial e das diferenças no uso do solo.

Destarte, a paisagem urbana apresenta-se como um produto histórico e social, revelando em sua aparência a essência dinâmica concebida pela materialização do trabalho da sociedade. Assim, a cidade é mais do que as construções e o deslocamento das pessoas. Segundo Lefebvre (1991), há conceitos importantes para o entendimento desta questão, como a diferenciação entre a cidade e o urbano.

Talvez devêssemos introduzir aqui uma distinção entre a cidade - realidade presente, imediata, dado prático, sensível, arquitetônico - e por outro lado o "urbano", realidade social composta de relações a serem concebidas, construídas ou reconstruídas pelo pensamento. Todavia, [...]. A vida urbana, a sociedade urbana, numa palavra "o urbano" não pode dispensar uma base prática-sensível, uma morfologia (LEFEB VRE,1991, p.49).

Para Bernardelli (2006), a cidade não deve ser vista somente a partir de sua materialidade, mas entendê-la como meio, condição e produto da sociedade, tendo em suas formas a manifestação concreta das contradições sociais presentes e sendo seu conteúdo a expressão dessas contradições. Neste sentido a cidade é concebida como espaços descontínuos, ou seja, partes fragmentadas e desiguais unidas na construção do todo.

Carlos (1997) apresenta a cidade como a própria relação dos homens entre si e com a natureza, lembrando ainda que o significado da cidade tem em seu cerne a dimensão humana. Por outro lado, ao estudarmos a cidade não podemos esquecer de que a mesma é um campo de lutas através das quais se determina o uso e o processo de apropriação do solo. Compreendendo a cidade como a materialização dos elementos urbanos, a sua apreensão pode ser concebida através da visualização da paisagem e da sua modificação no decorrer dos anos. 
adquire um a nova dimensão; específica de um determinado estágio do processo de trabalho vinculado à reprodução do capital (CARLOS, 1994, p.56).

A essência da paisagem, todavia, é compreendida a partir da análise do espaço urbano sobre as desigualdades e contradições, que se solidificam na sua construção, de forma que a sua modificação é perceptível numa mesma cidade, a depender das relações sócio-econômicas e culturais que ali se estabelecem, resultando na composição de espaços fragmentados diferenciados, principalmente pelo seu conteúdo social.

Segundo Santos (1997), a paisagem não se cria de uma só vez, mas por acréscimos, substituições; a lógica pela qual se fez um objeto no passado era a lógica da produção daquele momento. Uma paisagem é escrita sobre a outra, é um conjunto de objetos que têm idades diferentes, é uma herança de muitos diferentes momentos.

A partir da análise das divisões social e territorial do trabalho, encontra-se neste parâmetro produtivo e de reprodução do capital a paisagem como uma categoria de suma importância para compreensão da apropriação diferenciada e fragmentada dos espaços. Com a alteração da sociedade no decorrer dos tempos, o jeito de agir, trabalhar e de se relacionar do homem vem sofrendo grandes modificações, tornando-se cada vez mais complexas e ativas em decorrência das inovações tecnológicas.

As novas técnicas exigem um aperfeiçoamento, ou seja, a substituição das formas de produção e da configuração territorial. Nas cidades essas metamorfoses são mais freqüentes, resultado do berço do conhecimento científico localizado em seus limites. A cada nova descoberta o homem cria diferentes maneiras de se utilizar o meio para facilitar a vida e tentar superar o seu grau de dependência, transformando-o e aumentando seus domínios.

Assim como o processo de urbanização, intensificado pela evolução tecnológica, o crescimento populacional também representa um fator relevante nas transformações espaciais, e consequentemente nas degradações ambientais. Esta última, principalmente, é acentuada a partir do modelo padrão de produção e consumo adotado pela sociedade. Sobre isso, Loureiro (2002) coloca que o problema não está em toda tecnologia [...] as distorções situam-se no uso que se faz da mesma, no âmbito de um sistema que exclui e marginaliza a maioria do processo produtivo e torna a tecnologia o aparato principal para a proliferação de bens de consumos supérfluos, descartáveis e ambientalmente nocivos (LOUREIRO, 2002, p.38).

Como os efeitos da urbanização são intensos e localizados, os impactos ambientais concentram-se de acordo a necessidade de modificações e extração de recursos naturais. A redução da natureza primitiva apresenta a configuração dos novos espaços com suas funcionalidades. 
Estes recortes espaciais representam através da paisagem a sociedade que se edificou em classes, e conseqüentemente, reproduz as desigualdades integrantes deste meio social. É o que afirma Corrêa (1995)

\begin{abstract}
A grande cidade capitalista constitui, também, o lugar onde o meio ambiente apresenta-se como a mais complexa espacialidade. Esta, por sua vez, constitui uma das bases da realização da sociedade de classes e, ao mesmo tempo, de sua reprodução. A espacialidade traduz-se, por outro lado, em recortes espaciais caracterizados, cada um, pela mesma natureza do conteúdo ambiental, isto é, fixos, fluxos, tipos humanos e sua problematização. (CORRÊA, 1995, p.156-157)
\end{abstract}

Neste sentido, a cidade fragmenta-se em ambientes com áreas de núcleos centrais, subcentros comerciais, áreas industriais, zonas periféricas, áreas residenciais de classe dominante, de classe média e classes populares. Esta fragmentação encontra-se articulada e constitui a problematização do espaço urbano, além de ser reflexo e condicionante social com as características próprias da sociedade que o criou. Desta forma, nos diferentes usos do espaço urbano surgem as simbologias que são adquiridas de acordo com as atividades desempenhadas em determinado local.

Assim, formam-se os bairros com características homogêneas pelo seu conteúdo social, os cortiços, as favelas, a classe média e alta, mas que se diferem na constituição da cidade. Estes bairros agregam as simbologias advindas de aspectos relevantes ao estilo de vida dos moradores conferindo- lhes peculiaridades marcantes, desde os traços culturais aos problemas sócioambientais.

Estas comunidades distintas que se formam com a diferenciação do espaço, promovem a segregação espacial, e também usufruem a cidade de forma distinta. A proximidade ou a acessibilidade de serviços são fatores que compõe o cotidiano dos citadinos. Corrêa (1997) conceitua:

\footnotetext{
Segregação, quer dizer, diferenciação residencial segundo grupos, significa diferencial de renda real - proximidade às facilidades da vida urbana como água, esgoto, áreas verdes, melhores serviços educacionais, e ausência de proximidade aos custos da cidade como crime, serviços educacionais inferiores, ausência de infra-estrutura etc. Se já existe diferença de renda monetária, a localização residencial implica em diferença maior ainda no que diz respeito à renda real. (CORRÊA, 1997, p.134)
}

Deste modo, a divisão social do espaço forma uma realidade mais visível entre os extremos, ou seja, entre aqueles que podem pagar por uma boa localização com qualidade dos serviços de infraestrutura, e aqueles que estão sujeitos ao que o seu poder de compra lhes garante, como por exemplo, um lote de terra distante do seu local de trabalho, carente de serviços como, iluminação pública, esgoto, calçamento entre outros. Assim, a dinâmica social é acompanhada por mudanças na produção do espaço, em que segmentos sociais excluídos são capazes de 
construir de acordo as suas necessidades, abandonando uma lógica predeterminada, em prol da melhoria na qualidade de vida.

É neste contexto onde emergem as relações antagônicas das classes é que a degradação ambiental associada às desigualdades sociais se faz presente na organização urbana. Ratifica-se então, que a cidade é um produto social, ou seja, construída por todos os citadinos, mas nem todos a utilizam igualmente.

\section{PLANEJAMENTO URBANO}

A relação conturbada entre o desenvolvimento e a degradação ambiental se dá principalmente pela falta de planejamento urbano. Entretanto, as consequiências ao meio ambiente se estendem à sociedade, na medida em que os efeitos dos desequilíbrios ambientais atingem diretamente as pessoas, como ressalta Bergamo (2006) ao dizer que:

A questão ambiental urbana é considerada atualmente como tema de grande relevância, em decorrência das formas de uso/ocupação, que na maioria das vezes, não consideram as características naturais, levando a uma série de problemas sócio- ambientais, tais como: enchentes, alagamentos, desmatamento etc. (BERGAMO, 2006, p.14).

Neste sentido, o que se vê são construções em locais impróprios, como encostas de morros, proximidade a margens de rios, além de áreas de vegetação que deveriam ser preservadas. A apropriação destes espaços ocorre, principalmente, por pessoas de classe popular ou que não possuem sequer uma renda mensal, ou seja, sem condições financeiras para adquirirem terrenos e/ou casas em locais adequados para habitações.

Algo comum em determinadas cidades é a deterioração das serras por meio da retirada de vegetações, ocasionando solos desprotegidos e frágeis à ação pluvial. No período de chuvas, a falta da cobertura vegetal e a alta solubilidade do solo permitem que parte do material desça com as enxurradas. Além disso, a pavimentação comum nos centros urbanos reduz os canais de drenagem, fazendo com que as enxurradas não tenham para onde escoar. Assim, as águas invadem residências e podem causar acidentes de proporções diversas. Tendo como agravante, o lixo em locais inadequados, onde resíduos sólidos espalhados pelas ruas ou em terrenos baldios sem tratamento adequado, são carregados pelas enxurradas e entopem os bueiros que deveriam servir apenas para escoar as águas.

A pavimentação das vias urbanas e as grandes construções de concreto contribuem para a redução das áreas verdes, que consequentemente dificulta a dissipação dos gases poluentes comuns nos grandes centros. A poluição do ar é um fator de maior relevância quando se trata de qualidade de vida nas cidades de grande porte. 
Essa problemática demonstra claramente que não é possível dissociar os problemas ambientais dos sociais. A interligação inerente é um reflexo das questões econômicas vigentes, que exclui uma parcela da sociedade de usufruir um ambiente digno, com condições básicas. Desta maneira, reproduz desigualdades e privilégios em cidades que se apresentam num descompasso marcante entre extremos.

Destarte, o planejamento urbano no Brasil teve atenção especial a partir da Constituição Federal de 1988, em seu Artigo 182 como consta:

Art. 182 - A política de desenvolvimento urbano, executada pelo Poder Público municipal, conforme diretrizes gerais fixadas em lei, tem por objetivo ordenar o pleno desenvolvimento das funções sociais da cidade e garantir o bem-estar de seus habitantes.

$\S 1^{\circ}$ - O plano diretor, aprovado pela Câmara Municipal, obrigatório para cidades com mais de vinte mil habitantes, é o instrumento básico da política de desenvolvimento e de expansão urbana.

$\S 2^{\circ}$ - A propriedade urbana cumpre sua função social quando atende às exigencies fundamentais de ordenação da cidade expressas no plano diretor. (BRASIL, 1988).

Diante disso, o Estatuto da Cidade, Lei $\mathrm{n}^{\circ}$. 10257/01 regulamenta o Artigo 182 da Constituição e estabelece normas de ordem pública e interesse social, a partir da regulamentação do uso do solo urbano e promoção de uma cidade sustentável. Competem aos municípios à verificação de projetos, edificações, vistorias, conclusão de obras, conforme o art. $2^{\circ}$ da Lei $n^{\circ} .10 .257$, de 10 de julho de 2001:

II - gestão democrática por meio da participação da população e de associações representativas de vários segmentos da comunidade na formulação, execução e acompanhamento de planos, programa de projetos de desenvolvimento urbano;

$\mathrm{V}$ - oferta de equipamentos urbanos e comunitários, transporte e serviços públicos adequados aos interesses e necessidades da população e características locais (BRASIL, 2001, p.4).

Deste modo, a participação da população é um condicionante básico para que a sociedade possa ter o direito de cidadania fortalecido, a partir do momento que pode opinar sobre a configuração do espaço urbano. Isso acontece através de uma gestão democrática quando a comunidade é consultada nas decisões orçamentárias e mudanças sobre o destino da cidade, por meio de debates, conferências, audiências públicas e outros instrumentos de política urbana.

Para tanto, o surgimento de um ambiente ecologicamente equilibrado deve ser continuamente revisto por meio das ações do poder público e da sociedade civil, no intuito de atender o que rege a Política Ambiental Urbana amparada pelo Artigo 225 da Constituição:

Art. 225.Todos têm direito ao meio ambiente ecologicamente equilibrado, bem de uso comum do povo e essencial à sadia qualidade de vida, impondo-se ao Poder Público e à 
coletividade o dever de defendê-lo e preserva-lo para os presentes e futuras gerações (BRASIL, 1988). Partindo deste pressuposto, uma cidade sustentável acontecerá no momento em que houver o compromisso e participação de todos, sendo, portanto, um bem comum e essencial à qualidade de vida. Vale ressaltar, que a regulamentação do uso do solo por meio do ordenamento urbano deve corresponder ao interesse social, o que significa garantir a dignidade da pessoa humana.

Portanto, compete aos órgãos municipais promover por meio do ordenamento da cidade, uma política de controle e gestão dos recursos naturais que garanta a qualidade de vida da população. Vale ressaltar, que quando se tem em mente o bem-estar coletivo, a partir da compreensão de que o meio urbano é dinâmico, e, portanto, as cidades se expandem, faz-se necessário agir com precisão na busca da sustentabilidade. Neste sentido, a comunidade tem que tomar conhecimento dos seus direitos e deveres quanto ao ordenamento urbano, para tanto, é fundamental socializar que as leis são instrumentos disponíveis a serem aplicados.

\section{A SOCIEDADE DE CONSUMO}

Além dos impactos sofridos pela apropriação dos espaços na construção das cidades, bem como as questões cotidianas resultantes da ausência de organização na construção das mesmas, o meio ambiente ainda é atingido pelo modelo econômico, cujo consumo exacerbado se apresenta como uma de suas principais características.

\footnotetext{
A relação entre o crescimento econômico, perdas ambientais e desenvolvimento científico e tecnológico já despertava o interesse dos movimentos ambientalistas das décadas de 60 e 70, o que, aliado aos reclamos da sociedade civil organizada veio a compor uma força crítica aos modelos de desenvolvimento industrial, tanto capitalista, quanto socialista, e despertar uma nova consciência, atenta à dimensão ambiental da realidade. A partir de então a percepção dos problemas ambientais decorrentes do desenvolvimento, ou "mal desenvolvimento", expressão usada por Sachs (1986, p. 94), começa a ser mais efetiva. (MOREIRA \& RUWER, 2020)
}

A atual sociedade moderna, urbana e industrial é dedicada à produção e aquisição crescentes de bens de consumo cada vez mais diversificados. Para a sobrevivência dessa sociedade é essencial que sejam criadas necessidades de uso de novos produtos, pois, logo que um produto aparece no mercado, ele deve ser consumido intensamente e em seguida substituído por outro.

Essa rotatividade de produtos e serviços é fruto das inovações tecnológicas trazem comodidade e rapidez à vida das pessoas, eliminando os desconfortos e minimizando os efeitos das forças naturais. Os aparelhos eletrônicos, os descartáveis, os automóveis, as praticidades da energia elétrica, da água e gás encanados. Todos e mais alguns desses elementos tão comuns nos centros urbanos são responsáveis por impactos profundos ao meio ambiente, já que necessitam dos recursos naturais para existirem. Em concordância, Penna (1999), enfatiza que: 
As atividades humanas de alto consumo de energia representam - no seu conjunto - um ataque em larga escala aos ecossistemas terrestres e aos recursos que deles representam. Estes incluem ao controle da mistura de gases na atmosfera e, portanto, do clima; o ciclo hidrológico que nos fornece o fluxo de água doce; a produção e a manutenção de solos férteis; a disposição de rejeitos; a reciclagem de nutrientes essenciais à agricultura... (PENNA, 1999, p.24).

Portanto, a busca pela satisfação, inerente a natureza humana, ocasiona transtornos que aos poucos a sociedade começa a sentir os efeitos. O excesso de gases na atmosfera que juntamente com o desmatamento torna o ar cada vez mais poluído, a contaminação dos solos e rios por dejetos e resíduos sólidos. A cada dia a redução da qualidade e da quantidade dos recursos naturais é mais visível, e nas áreas urbanas as consequências deste novo cenário traz transtornos à saúde humana.

\section{CONSIDERAÇÕES FINAIS}

Destarte, a formação de uma consciência política e ambiental é um grande desafio para a sociedade, pois é necessário pensar sobre modelos de desenvolvimentos economicamente viáveis, responsáveis e socialmente aceitáveis, que cooperem para redução da miséria e para a conservação dos recursos naturais.

Diante do dinamismo do meio social, percebe-se a relevância da conciliação entre crescimento urbano e as questões ambientais. Não há como negar que o processo de industrialização, e, consequentemente, urbanização promoveram um intenso desequilíbrio ao meio ambiente, a partir do momento que a apropriação do meio natural aconteceu de maneira desordenada. Assim, a perpetuação deste modelo, prevalece no momento atual em determinados espaços, fragmentando e dificultando ações que venham a contemplar o bem estar social.

Deste modo, a complexidade inerente as relações tecidas no âmbito das cidades, são merecedoras de atenção e envolvimento contínuo da sociedade, por meio da participação na política urbana de ordenamento de uso do solo. O Plano Diretor Urbano, não deve ser visto como algo que compete apenas ao poder público, mas sim, um instrumento de gestão democrática com a presença da população na formulação dos planos a serem desenvolvidos.

Portanto, diante da reflexão empreendida percebe-se que a depender do conteúdo social, principalmente, nos lugares carentes de infraestrutura adequada, e estes são os espaços ocupados pelas classes populares, a degradação ambiental é fator dominante, demonstrando que esta parcela da sociedade permanece excluída. 


\section{REFERÊNCIAS}

BERGAMO, Eliana de Paula. Legislação ambiental e urbana: A necessidade do planejamento ambiental em bacias hidrográficas urbanizadas na escala municipal. GEONORDESTE, Ano XV, $\mathrm{n}^{\circ} 1, \quad 2006 . \quad$ Disponível em: http://www.posgrap.ufs.br/periodicos/pdf/revista_geo_06_1/Eliana.pdf. Acesso em 26/12/2008.

BERNARDELLI, Mara Lúcia F. da Hora. Contribuição ao debate sobre o urbano e o rural. IN: SPOSITO, Maria E. B, WHITACKER. Artur M. Cidade e Campo: relações e contradições entre urbano e rural. São Paulo: Expressão Popular, 2006.

BRASIL. Constituição da República Federativa do Brasil. Brasília: Senado Federal, 1988.

_ $\quad$. Lei 10.257 de 2001. O Estatuto da Cidade. Disponível em:

<http://www.actabrasil.hpg.com.br> Acesso em: setembro. 2008 CARLOS, Ana Fani A. A (re)produção do espaço urbano. São Paulo: Editora da Universidade de

São Paulo, 1994.

A cidade. $3^{\text {a }}$ Ed. São Paulo - SP. Geografia Contexto. Repensando a Geografia, 1997. CORRÊA. Roberto Lobato. O espaço urbano. $3^{\text {a }}$ Ed. São Paulo: Ática, 1995.

CORRÊA, Roberto Lobato. Trajetórias geográficas. Rio de Janeiro: Bertrand Brasil, 1997. LEFEB VRE, Henry. O direito à cidade. $1^{\text {a }}$ ed. - São Paulo: Moraes, 1991.

LOUREIRO. Carlos F. B, LAYRARGUES. P. P, CASTRO R. S. de (orgs.) Sociedade e meio ambiente: a educação ambiental em debate. $2^{\circ}$ ed. - São Paulo: Cortez, 2002.

MOREIRA, I. D. S. .; RUWER, L. M. E. . Mundo do trabalho, serviço social e desenvolvimento sustentável. Latin American Journal of Development, v. 2, n. 5, p. 206-227, 30 Oct. 2020. Disponível em: https://latinamericanpublicacoes.com.br/ojs/index.php/jdev/article/view/68/58. Acesso em 03/07/2021.

PENNA, Carlos Gabaglia. O estado do planeta. Rio de Janeiro: Record.1999

SANTOS, Milton. A urbanização brasileira. São Paulo: Hucitec, 1997.

. Metamorfoses do espaço habitado. $5^{\text {a }}$ ed. - São Paulo: Hucitec, 1997.

SCHWENK, Lunalva Moura; CRUZ, Carla Bernadet M. Os processos espaciais como mediadores na transformação do espaço geográfico. Maringá, v.26, n.2, p.287-299, 2004.

SORRETINO, Marcos. Desenvolvimento Sustentável e Participação: algumas reflexões em voz alta. IN: LOUREIRO, C.F.Bernardo; LAYRARGUES, P. Pomier; CASTRO, R. Souza de. (orgs.) Educação Ambiental: repensando o espaço da cidadania. São Paulo: Cortez, 2002. 